\section{OPTIMIZATION OF GLYCEROL MONOLAURATE (GML) SYNTHESIS FROM GLYCEROL AND LAURIC ACID USING DEALUMINATED ZEOLITE $Y$ CATALYST}

Didi Dwi Anggoro*, Herawati Oktavianty, Bagas Prasetya Kurniawan, Roynaldy Daud

Department of Chemical Engineering, Faculty of Engineering, University of Diponegoro, Jl. Prof. Sudharto, Tembalang, Semarang, 50239, Indonesia
Article history

Received

14 January 2019

Received in revised form

28 April 2019

Accepted

14 May 2019

Published online

25 June 2019

*Corresponding author dididwianggoro@lecturer.undip.ac.id

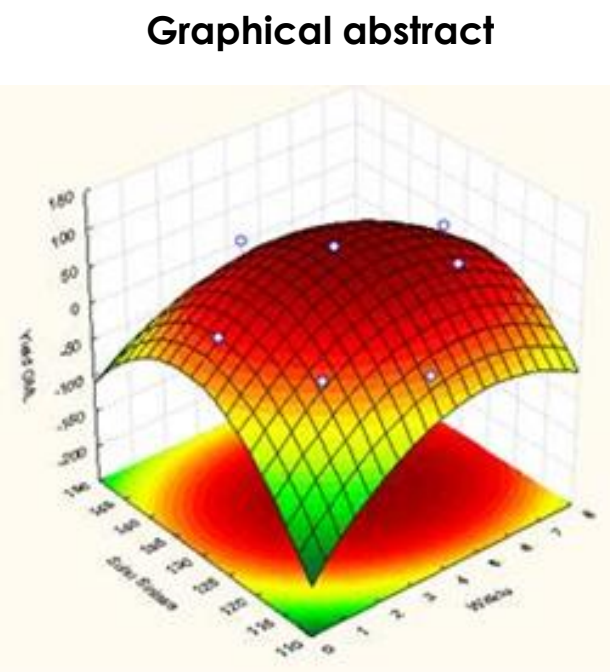

\begin{abstract}
Glycerol Monolaurate (GML) is used as a surfactant, preservative and emulsifier in food, besides it can be used in cosmetics and medicines. This study obtained to optimize GML synthesis from glycerol and lauric acid. It consisted of two steps, dealumination of zeolite $Y$ catalyst and optimization of GML synthesis. At dealumination process, zeolite $\mathrm{Y}$ will reacted with $\mathrm{H}_{2} \mathrm{SO}_{4}$ solution and aquadest with temperature at $60^{\circ} \mathrm{C}$ for 4 hours, then drying with temperature at $110^{\circ} \mathrm{C}$ for 1 hour, then furnace with temperature at $500^{\circ} \mathrm{C}$ for 3 hours. The synthesis of GML held by reacting glycerol and lauric acid using dealuminated zeolite $\mathrm{Y}$. The synthesis of GML analyzed using GC-MS to determine the structure, molecular weight, and conversion of GML produced. This study obtained GML optimization to produce the greatest yield of GML. The best test results obtained is $90.75 \%$ of $\mathrm{GML}$ yield and the estimated value of optimization at temperature $130^{\circ} \mathrm{C}$ for 4 hours, and the mole ratio of lauric acid with glycerol 1: 7.5 (with the mass of lauric acid is $25 \mathrm{~g}$, and the mass of glycerol is $87.654 \mathrm{~g}$ ).
\end{abstract}

Keywords: glycerol monolaurate, glycerol, zeolite Y, dealumination, optimization

(c) 2019 Penerbit UTM Press. All rights reserved

\subsection{INTRODUCTION}

Glycerol monolaurate (GML) is used as a surfactant, preservative and emulsifier in food, besides it can be used in cosmetics and medicines. As a non-ionic surfactant containing a hydrophilic and hydrophobic group, GML can be used as a nutritional supplement [1]. Therefore glycerol which is a by-product of transesterification of biodiesel can be produced into GML so that the selling value becomes higher. GML is obtained from the esterification process by reacting glycerol with lauric acid added with the aid of a catalyst with N2 gas flowing during the process [2]. The esterification reaction in the synthesis of GML using the aid of an acid or base catalyst is usually carried out at high temperatures. In addition to the temperature, the ratio of glycerol with lauric acid, the concentration of the catalyst and the exact time of the synthesis process, can produce GML with a high yield. 
Zeolite $Y$ is a type of crystalline alumino silicate with a micro-sized cavity that has a frame size of about 0.74 $\mathrm{nm}$ that shown in Figure 1 [3].

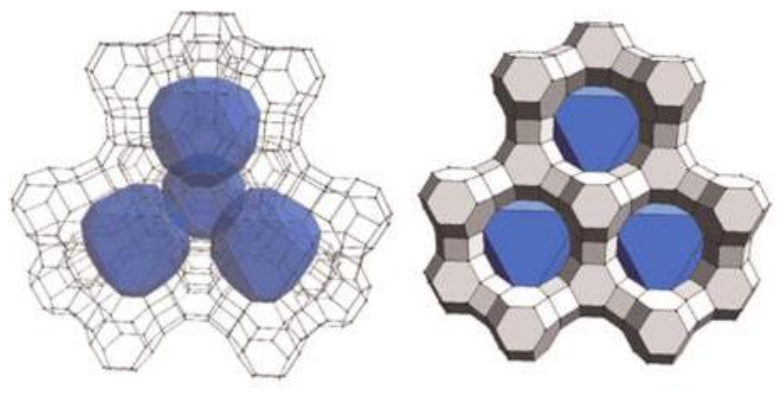

Figure 1 Zeolite Y Framework Structure

It is a zeolite which has the largest application in the catalysis process and belongs to the category of faujasites. Faujasites are a type of mineral group in zeolite which is a silicate mineral. Faujasite itself can contain Faujasite-Na, Faujasite-Mg and Faujasite-Ca [4].

Zeolite- $Y$ is more stable at high temperatures than zeolite $X$. This catalyst produces $20 \%$ more petrol (gasoline) than zeolite-X. Most zeolites, synthesized in the form of sodium, and common materials in the synthesis process of $Y$ zeolite are sodium aluminate, $\mathrm{NaOH}$ and silica sol (colloidal silica suspension) and usually the product has a composition of $\mathrm{Na}_{2} \mathrm{O} \cdot \mathrm{Al}_{2} \mathrm{O}_{3} \cdot 3 \mathrm{SiO}_{2} \cdot 5 \mathrm{H}_{2} \mathrm{O}$. However, in preparing $\mathrm{a}$ hydrogen compound which is composed of zeolite $Y$, it is quite difficult, because the framework of faujasite will be damaged if it comes into contact with a strong acid solution. But this can be overcome by replacing the $\mathrm{Na}^{+}$ion with $\mathrm{NH}_{4}{ }^{+}$ions and increasing the temperature, which can cause ammonium ions (which are now in zeolite) to decompose $\mathrm{NH}_{3}$ gases leaving zeolite, and $\mathrm{H}^{+}$ions remain on zeolites [3].

Dealumination is the process of releasing Al atoms from zeolites. Dealumination is done to increase the $\mathrm{Si}$ / Al ratio. Changes in the $\mathrm{Si} / \mathrm{Al}$ ratio of a material will affect the nature of the material. The higher the Si / Al ratio of a material will increase the acidic site of the zeolite itself, this acid site is a site that functions as the active side of zeolite, dealumination will also cause the material to be more hydrophobic. Dealumination is the most important commercial method for getting the desired amount of $\mathrm{Al}[5,6]$.

In this study, the synthesis of GML was carried out with the help of a Y CBV-712 zeolite catalyst that had been dealuminated. This study includes 2 stages, namely dealumination of zeolit $Y$ catalysts and optimization of GML synthesis. This study also simultaneously reviews the research conducted by Machado et.al [7] about the synthesis of GML with zeolite catalysts. With the fixed variables used are the number of catalysts and the speed of stirring, and the changing variables used are temperature, time, and mole ratio of lauric acid with glycerol.

Research conducted by Machado et al., [7] synthesis of GML from lauric acid and glycerol as the main material with the help of Beta Zeolite, $\mathrm{Y}$ Zeolite and Mordenite Zeolite with different Si / Al ratios as catalysts. Reaction conditions such as stirring speed, temperature, mole ratio of glycerol and lauric acid and catalyst mass are optimized to reduce homogeneous reactions and limited reactions due to varying effects. In the use of $Y$ Zeolite, GML yield is obtained at a high Si / Al ratio. This is related to the increasing acidity of zeolites with low Al. This Si / Al ratio in $Y$ Zeolites ranges from 25-30 in $Y$ Zeolite. An increase in the Si / Al ratio affects the GML yield that can be produced. The dealumination process can increase the ratio of $\mathrm{Si} / \mathrm{Al}$ so that it can increase zeolite activity and can produce a greater GML yield.

Fadhil Rifai, et al. [8] found that the increase in dealumination temperature will affect the crystallinity and surface area of the zeolite $Y$ catalyst, as well as the variations in the yield of GML produced. The increase in dealumination temperature increases the crystallinity of the decomposed $Y$ zeolite. This is because zeolite containing $\mathrm{Si}-\mathrm{Al}-\mathrm{O}$ bonds will lose the alumiunium metal that is expelled from the zeolite framework will be even greater. But at higher temperatures, the framework will be damaged and changes in the structure of zeolite will cause the crystallinity of $\mathrm{Y}$ zeolite to drop dramatically. The increase in dealumination temperature, also increases the surface area of the $Y$ Zeolite catalyst, because it affects the pores of the catalyst, where the pores will be smaller, and increase the surface area of the zeolite $Y$ catalyst. but with higher temperatures, where there has been damage to some pores as well as a catalyst framework that causes a decrease in the yield of GML produced.

This articles estimates the optimization of synthesis temperature and synthesis time, and glycerol mass of GML synthesis using response surface methodology (RSM). The temperature used were 120, 130 and $140^{\circ} \mathrm{C}$, time used were 2,4 and $6 \mathrm{~h}$ and glycerol mass used were $34,59,63,415$ and $992,24 \mathrm{~g}$, resulting in a two-level experimental design, with 16 experiments. Empirical parameters were estimated with standard least-square procedure, using the Design Expert Statsoft software Statistica version 6.0 2001.

\subsection{METHODOLOGY}

\subsection{Dealumination Process of Zeolite $Y$}

Zeolite Y (10 g) was dealuminated by treating it with $\mathrm{H}_{2} \mathrm{SO}_{4}$ solution (mixed the $44,65 \mathrm{ml}$ of $\mathrm{H}_{2} \mathrm{SO}_{4}$ by 55,35 $\mathrm{ml}$ of aquadest). The dealumination treatment was carried out in a three neck rounded flask with stirrer for mixing the shulfuric acid with zeolite $Y$, and dealuminated with the temperature of $60^{\circ} \mathrm{C}$ for 4 hours. Then, zeolite that have been dealuminated, calcinated with a furnace at $500^{\circ} \mathrm{C}$ for 3 hours. Dealuminated zeolite $Y$ then tested to synthesize $\mathrm{GML}$ using a glycerol and lauric acid [9]. 


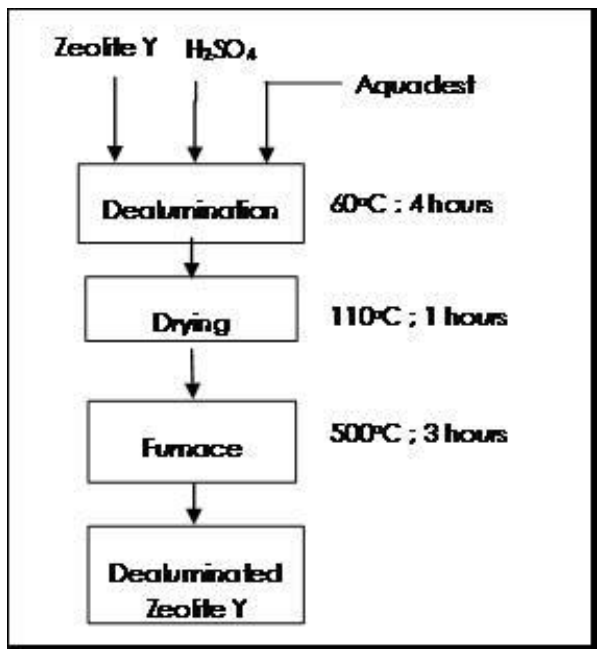

Figure 2 Flowchart of Dealumination Process of Zeolite $Y$

\subsection{GML Synthesis}

GML synthesis was carried out in the beaker glass with stirrer (speed setting was 300 rpm)for mixing the glycerol and lauric acid and also the dealuminated zeolite $Y$. Then setting the temperature and time of synthesis. Figure 3 shows the flowchart of $\mathrm{GML}$ synthesis.

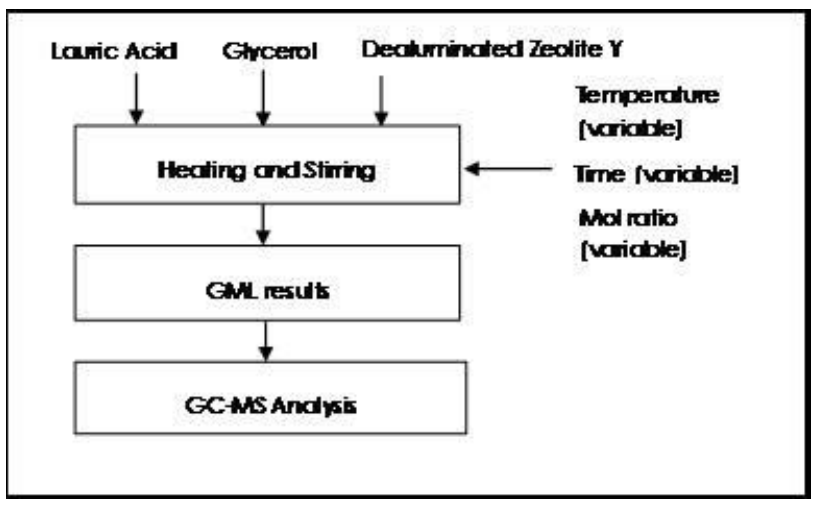

Figure 3 Flowchart of GML Synthesis

\subsection{Optimization Procedure}

The empirical models were used to analyze the influence of the process variables on the response factors. Second order polynomial models were used to verify the linear and quadratic effect of the process variables and their linear and quadratic interactions. The study used normalized process variables, in order to compare the relative importance of model parameters and to obtain independent linear parameter. Therefore, process variables assumed the values $(-1),(0)$, or (+1) for minimum, central and maximum. For temperature as an example, the value of 120,130 and $140^{\circ} \mathrm{C}$ stand for minimum, central and maximum temperature, respectively (Table 1).

The optimization method based on RSM (Response Surface Methodology) involved three major steps: design of experiment using statistical approach, coefficient estimation based on mathematical model and response prediction, and finally model adequacy check. The equation model is tested with analysis of variance (ANOVA) with $99 \%$ degree of confidence. The RSM output such as contour and 3D graphic surface plots provide the optimum and most influential variable for GML yield. According to central composite design, the total number of experiment combination is $2^{k}+2^{k}+n_{0}$, where $k$ is the total number of independent variables and $n_{0}$ is the number of experiments repeated at the center point $(10 ; 11 ; 12 ; 13)$. In this case, no $=2$.

The variable $x_{i}$ were coded as $x_{i}$ according to Equation (1). The basis of forming a polynomial equation is given in Equation (2).

$$
\begin{gathered}
x_{i}=\frac{X_{1}-X_{0}}{\Delta X} ; \quad i=1,2,3, \ldots, k \\
Y=\beta_{0}+\sum_{j=1}^{2} \beta_{j} X_{j}+\sum_{j=1}^{2} \beta_{j j} X_{j}^{2}+\sum_{i<j} \beta_{i j} X_{i} X_{j}
\end{gathered}
$$

Where $Y=$ estimated result, $\beta_{0}=$ intercept coefficient, $\beta_{i}=$ linear coefficient $X_{j}, \beta_{j j}=$ quadratic coefficient $X_{j}, \beta_{i j}=$ interaction coefficient, $X_{i}$ and $X_{j}=$ independent variable. As for the range of independent variables, levels, and experimental designs are appointed based on the Central method Composite Design.

The low, middle and high levels for all these variables (independent variables) were based on prior screening from literature review and accordingly, temperatures of 120,130 and $140^{\circ} \mathrm{C}$ were chosen for variable $X_{1}$ (operating temperature); 2,4 and $6 \mathrm{~h}$ for $X_{2}$ (operating time) and 34,59, 63,415 and $92,24 \mathrm{~g}$ for $X_{3}$ (glycerol mass) as shown in Table 1.

Table 1 The levels of variables chosen for trials

\begin{tabular}{cccc}
\hline & $\begin{array}{c}\text { Temperature, } \\
\boldsymbol{X}_{1}\left({ }^{\circ} \mathbf{C}\right)\end{array}$ & Time, $\boldsymbol{X}_{2}(\mathbf{h})$ & $\begin{array}{l}\text { Glycerol mass, } \\
\boldsymbol{X}_{3}(\mathbf{g})\end{array}$ \\
\hline$-\alpha$ & 113 & 0,64 & 14,9373 \\
-1 & 120 & 2 & 34,59 \\
0 & 130 & 4 & 63,415 \\
+1 & 140 & 6 & 92,24 \\
$+\alpha$ & 147 & 7,36 & 111,8927 \\
\hline
\end{tabular}

The actual design experiment is shown in Table 2. It was found that a total of 16 runs were necessary in order to optimize processing parameter for enhanced GML yield. The design experiment was carried out using the Design Expert Statsoft software "Statistica" version 6.02001. 
Table 2 Experimental plan for optimization process

\begin{tabular}{cccc}
\hline \multirow{2}{*}{ Run } & \multicolumn{3}{c}{ Independent Variables } \\
\cline { 2 - 4 } & $\begin{array}{c}\text { Temp } \\
\left({ }^{\circ} \mathbf{C}\right)\end{array}$ & $\begin{array}{c}\text { Time } \\
\text { (h) }\end{array}$ & $\begin{array}{c}\text { Glycerol } \\
\text { Mass }(\mathbf{g})\end{array}$ \\
\hline 1 & 120 & 2 & 34,59 \\
2 & 120 & 2 & 92,24 \\
3 & 120 & 6 & 34,59 \\
4 & 120 & 6 & 92,24 \\
5 & 140 & 2 & 34,59 \\
6 & 140 & 2 & 92,24 \\
7 & 140 & 6 & 34,59 \\
8 & 140 & 6 & 92,24 \\
9 & 113 & 4 & 63,415 \\
10 & 147 & 4 & 63,415 \\
11 & 130 & 0,64 & 63,415 \\
12 & 130 & 7,36 & 63,415 \\
13 & 130 & 4 & 14,9373 \\
14 & 130 & 4 & 111,8927 \\
15 & 130 & 4 & 63,415 \\
16 & 130 & 4 & 92,24 \\
\hline
\end{tabular}

\subsection{RESULTS AND DISCUSSION}

\subsection{Acidity of Zeolite Y Catalyst}

Zeolite $Y$ was dealuminated using a sulphuric acid, basically a strong acid and could possibly damage the framework and also evicted Al from the zeolite framework. Thus, this cause a decreased cristallinity upon the zeolites that have been dealuminated. Dealuminated zeolite also usually change the structure and morphology of the zeolites, causing the changing of surface area, pore diameters and acidic power which disturbed the catalyst balance itself and affect the catalyst selectivity [14].

Zeolite $Y$ that been used in this study was the optimal condition of the previous study [9]. The results showed the changing of crystallinity in a better acid conversion rather than using the catalyst that never been dealuminated before. This means that, despite the changes of zeolites framework, the catalysts ability to accelerate the forming of other substrate (GML) is faster than the using of zeolite $Y$ without dealumination process. Acid conversion represents the content of free fatty acids produced from the glycerol synthesis, and in this case, is considered to be one of the main parameters that reflect the catalyst activity towards its ability to accelerate the forming of GML.

\subsection{Correlation between Synthesis Time and Temperature to GML Yield}

Table 3 shows the GML yield in the various variables. Analysis of Variance (ANOVA) was used to analyze the yield of GML as shown in Table 1, the significance of each factor in table 4 , tested using the value of $\mathrm{F}$ value and $\mathrm{p}$-value. A high $\mathrm{F}$-value and a $\mathrm{p}$-value value of $<0.05$ indicate that the variables significantly influence the observed response.
Table 3 GML Yield in Various Variables

\begin{tabular}{ccccc}
\hline Run & \multicolumn{3}{c}{ Variable } & Temp \\
\cline { 2 - 4 } & $\begin{array}{c}\text { Time } \\
\left.\mathbf{(}{ }^{\circ} \mathbf{C}\right)\end{array}$ & $\begin{array}{c}\text { Glycerol } \\
\text { (h) }\end{array}$ & $\begin{array}{c}\text { Mass } \\
\mathbf{( g )}\end{array}$ & $\begin{array}{c}\text { Gield } \\
\mathbf{( \% )}\end{array}$ \\
\hline 1 & 120 & 2 & 34,59 & 0 \\
2 & 120 & 2 & 92,24 & 0 \\
3 & 120 & 6 & 34,59 & 2,3 \\
4 & 120 & 6 & 92,24 & 76,66 \\
5 & 140 & 2 & 34,59 & 0 \\
6 & 140 & 2 & 92,24 & 3,32 \\
7 & 140 & 6 & 34,59 & 0 \\
8 & 140 & 6 & 92,24 & 0 \\
9 & 113 & 4 & 63,415 & 0 \\
10 & 147 & 4 & 63,415 & 20,75 \\
11 & 130 & 0,64 & 63,415 & 36,69 \\
12 & 130 & 7,36 & 63,415 & 56,76 \\
13 & 130 & 4 & 14,9373 & 24,1 \\
14 & 130 & 4 & 111,8927 & 87,19 \\
15 & 130 & 4 & 63,415 & 88,97 \\
16 & 130 & 4 & 92,24 & 90,75 \\
\hline
\end{tabular}

Table 4 Analysis Of Variance

\begin{tabular}{ccccc}
\hline Variant & Coefficient & F-Value & DF & p-value \\
\hline$X_{0}$ & 94,1904 & & & \\
$X_{1}$ & $-2,9292$ & 0,18492 & 1 & 0,682193 \\
$X_{1}{ }^{2}$ & $-33,7409$ & 14,17398 & 1 & 0,009345 \\
$X_{2}$ & 8,0146 & 1,37075 & 1 & 0,286073 \\
$X_{2}{ }^{2}$ & $-21,7861$ & 5,67059 & 1 & 0,054671 \\
$X_{3}$ & 13,5655 & 4,12522 & 1 & 0,088533 \\
$X_{3}{ }^{2}$ & $-18,4831$ & 3,63705 & 1 & 0,105129 \\
$X_{1} X_{2}$ & $-10,2850$ & 1,32350 & 1 & 0,293742 \\
$X_{1} X_{3}$ & $-8,8800$ & 0,98660 & 1 & 0,358927 \\
$X_{2} X_{3}$ & 8,8800 & 0,98660 & 1 & 0,358927 \\
\hline
\end{tabular}

Based on the results of ANOVA for GML yield, factor $X_{1}$ is the most significant factor, indicating with high F-value (14.17398) and low p-value(0.009345). The objective function of the results of this test is used to determine the optimal value of the synthesis temperature $\left(X_{1}\right)$, time $\left(X_{2}\right)$, and glycerol mass $\left(X_{3}\right)$. The relationship between operating variables to the GML yield response can be expressed in the $2^{\text {nd }}$ order polynomial mathematical equation based on the following equation:

$$
\begin{aligned}
Y= & 94,1904-2,9292 X_{1}-33,7409 X_{1}^{2}+8,0146 X_{2}- \\
& 21,7861 X_{2}{ }^{2}+13,5655 X_{3}-18,4831 X_{3}^{2}- \\
& 10,2850 X_{1} X_{2}-8,8800 X_{1} X_{3}+8,8800 X_{2} X_{3}
\end{aligned}
$$

The selection of order can be determined by looking at the value of the coefficient of determination, where the model with the highest coefficient of determination is the recommended model. In this study, the coefficient of determination $\left(R^{2}\right)$ for the $2^{\text {nd }}$ order polynomial mathematical equation has a value of 81.169 . which means that there is a match between experimental data and prediction data at $81.169 \%$. The model can be declared accurate if the value of $R^{2}$ exceeds $70 \%$ so 
it can be concluded that the value estimated by the model is close to the value obtained from the experimental results [15].

The regression coefficient of 81,169 shows a match between the predicted value and the results of the experimental data as shown in Figure 4, the straight line in Figure 6 is called the regression line. The regression line shows the best predictions of the dependent variable $(Y)$, on independent variables $(X)$. However, in reality (if ever), it is very rare to predict perfectly, and usually there are substantial variations of the points observed, around the regression line. Deviations from certain points of the regression line (predicted value) are referred to as residual values.

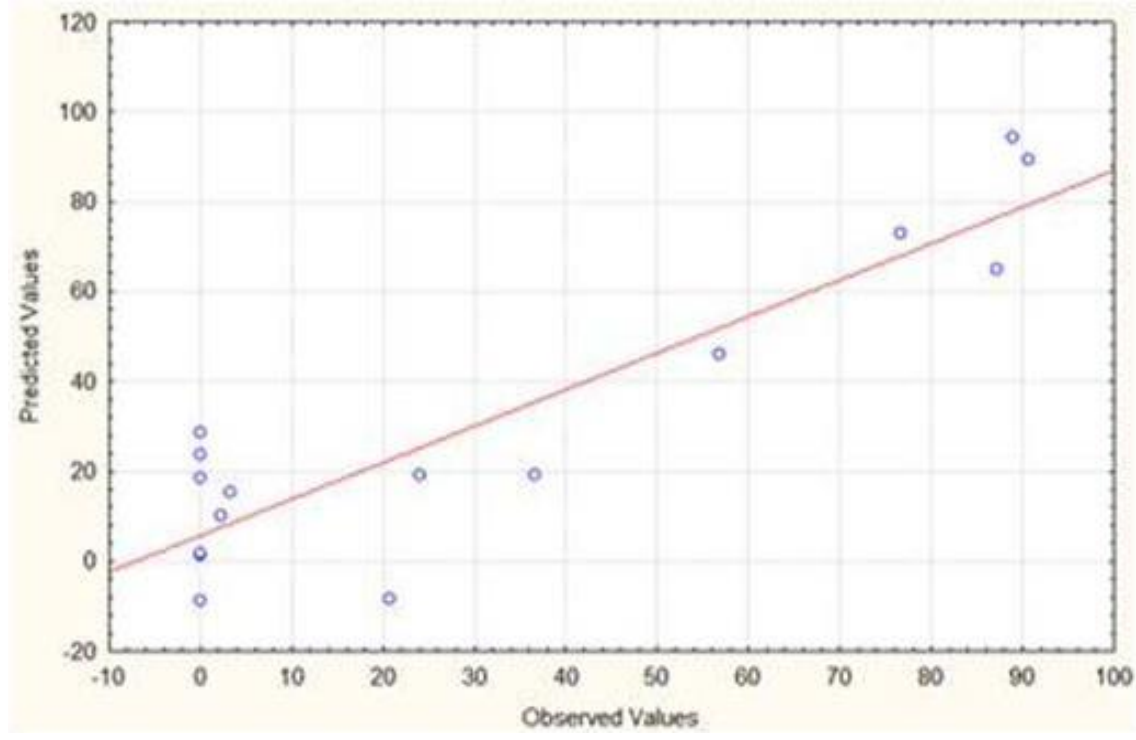

Figure 4 Relationship Between Predicted and Observed Value of GML Yield

In Figure 5, through a 2D contour graph, showing the relationship between time at 4 hours and the synthesis temperature of $130^{\circ} \mathrm{C}$ results in a higher yield of Glycerol Monolaurate (GML). This is seen from the color distribution, where at 4 hours and with the synthesis temperature of $130^{\circ} \mathrm{C}$, the red color distribution indicates that the obtained Glycerol
Monolaurat (GML) is high. In Figure 6, through 3D surface graphs, it shows the relationship between the time and the temperature of the synthesis that produces a curved surface. As seen in the figure, at the increase in synthesis time, the yield of the resulting Glycerol Monolaurat (GML) will increase at 4 hours.

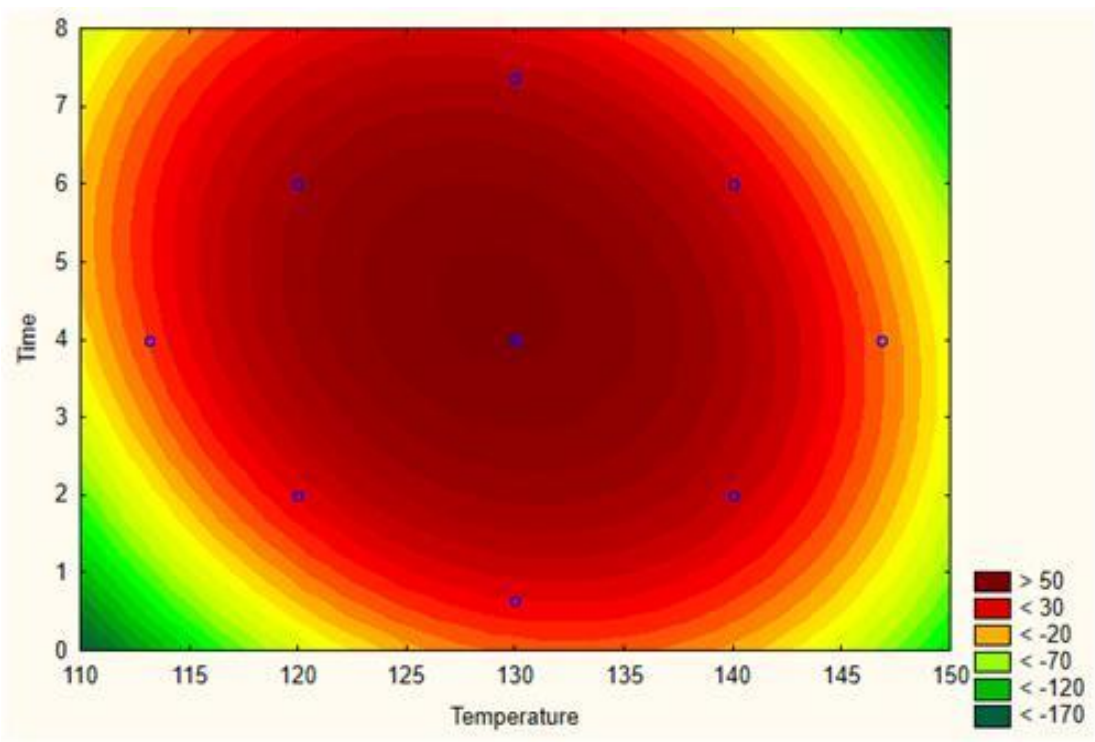

Figure 5 2D Contour Correlation between Time and Temperature of Synthesis to GML Yield 
GML that is formed until the synthesis time reaches 4 hours will be higher, but if the synthesis time exceeds 4 hours it will start to produce byproducts in the form of Glycerol Trilaurate (GTL). Meanwhile, when the synthesis temperature exceeds $130^{\circ} \mathrm{C}$, it also can increase the formation of GTL.

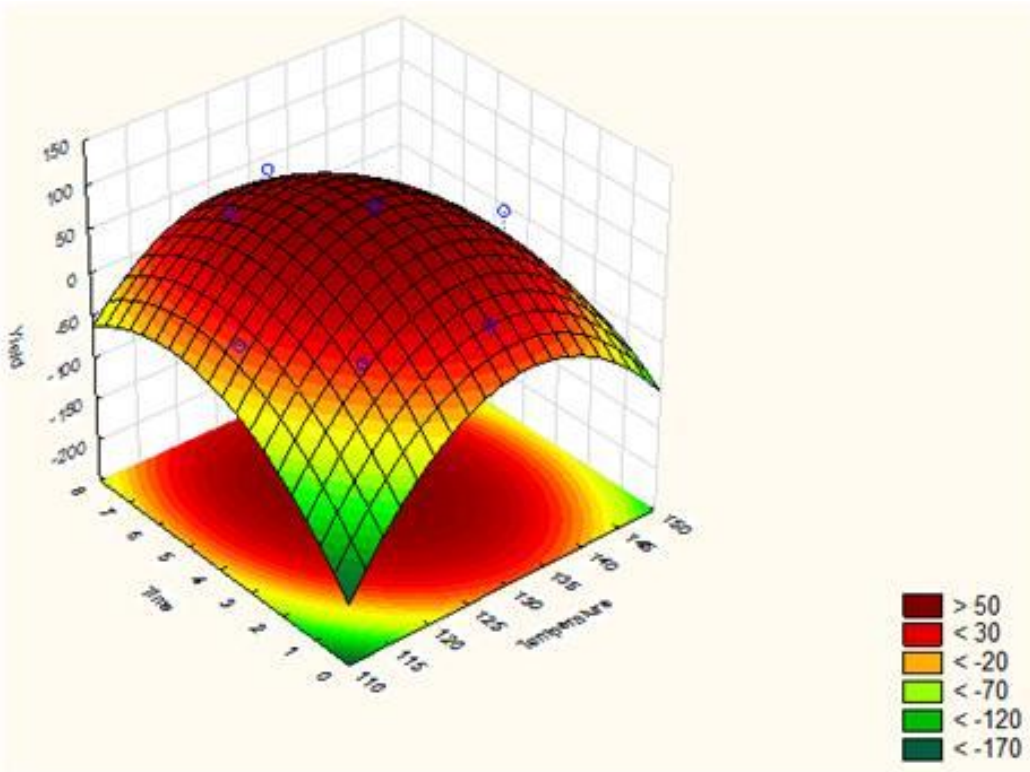

Figure 6 2D Surface Correlation between Time and Temperature of Synthesis to GML Yield

\subsection{Correlation between Glycerol Mass and Synthesis Temperature to GML Yield}

In Figure 7, through 2D contour graphs, the relationship of glycerol mass of 60-90 $\mathrm{g}$ and temperature of $130^{\circ} \mathrm{C}$ shows a higher GML yield response. This can be seen from the distribution of colors, where at 4 hours and the total mass of glycerol 60-90 $\mathrm{g}$, redder color distribution indicates that the GML yield obtained is high. In Figure 8, through a 3D surface graph, it shows the relationship between the glycerol mass and the temperature that produces a curved surface.
The results are obtained because when the glycerol mass is precisely at $87,654 \mathrm{~g}$, or the mole ratio of lauric acid to the mole of glycerol 1: 7.5 lexcess glycerol), GML will be obtained with the optimum amount. This is because making excess one of the reactants will cause the reaction equilibrium to shift towards the product, resulting in more products. In this condition, excess is made of glycerol because Glycerol has three hydroxy $(\mathrm{OH})$ groups which can easily capture fatty acids to form esters, so the more glycerol is used, the more GML will be produced.

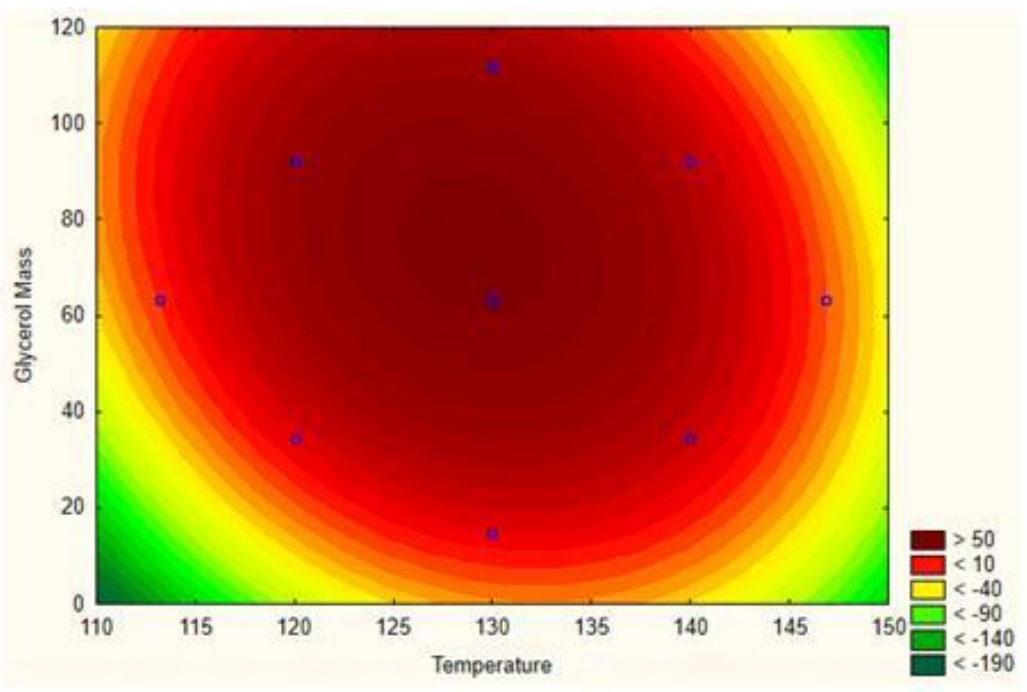

Figure 7 2D Contour Correlation between Glycerol Mass and Synthesis Temperature to GML Yield 


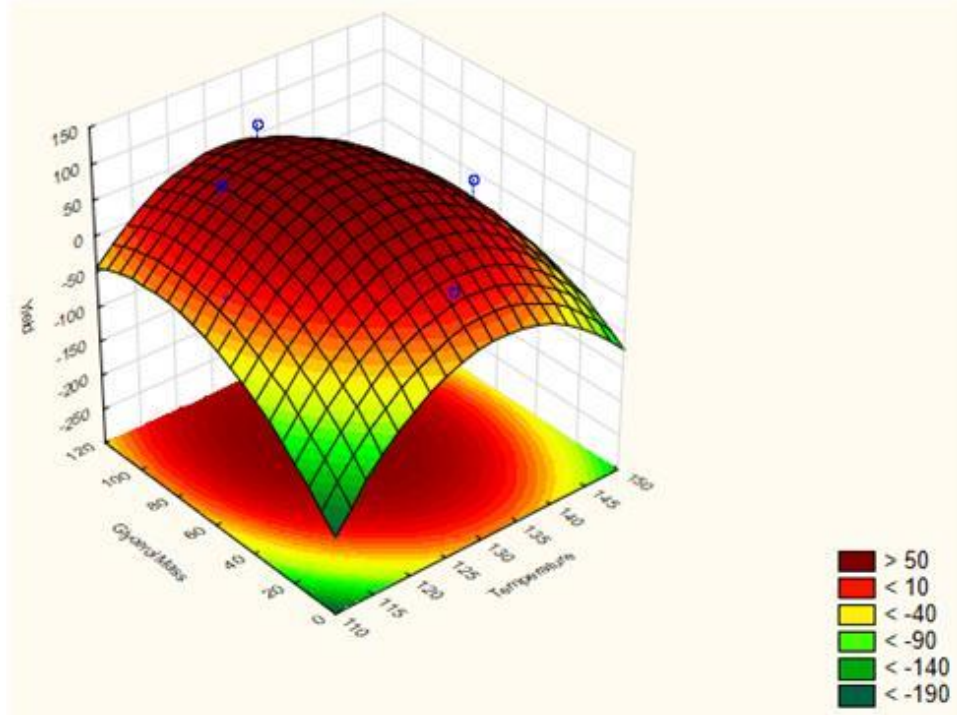

Figure 8 3D Surface Correlation between Glycerol Mass and Synthesis Temperature to GML Yield

\subsection{Correlation between Synthesis Time and Glycerol Mass to GML Yield}

In Figure 9, through a 2D contour graph, it shows the relationship between time at 4 hours and the glycerol mass in the range 60 - $90 \mathrm{~g}$ resulting in a higher $\mathrm{GML}$ yield response. This can be seen from the color distribution, where at 4 hours and the total glycerol 60-90 $\mathrm{g}$, the red color distribution indicates that the GML yield obtained is high. In Figure 10, through a 3D surface graph, it shows the relationship between time and the mass of glycerol which produces a curved surface.

Optimum GML yield obtained when the mass of glycerol used was $87,654 \mathrm{~g}$, or the mole ratio of lauric acid to glycerol 1: 7.5, with the optimum synthesis time of 4 hours. When the synthesis time exceeds 4 hours, it will start to produce byproducts in the form of Glycerol Trilaurate (GTL).

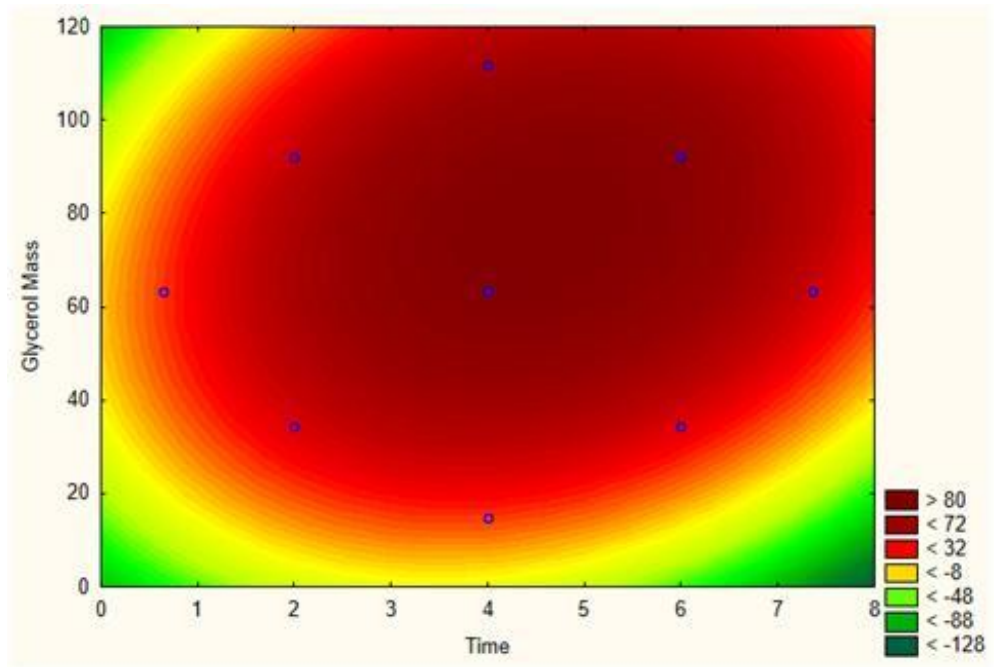

Figure 9 2D Contour Correlation between Synthesis Temperature and Glycerol Mass to GML Yield 


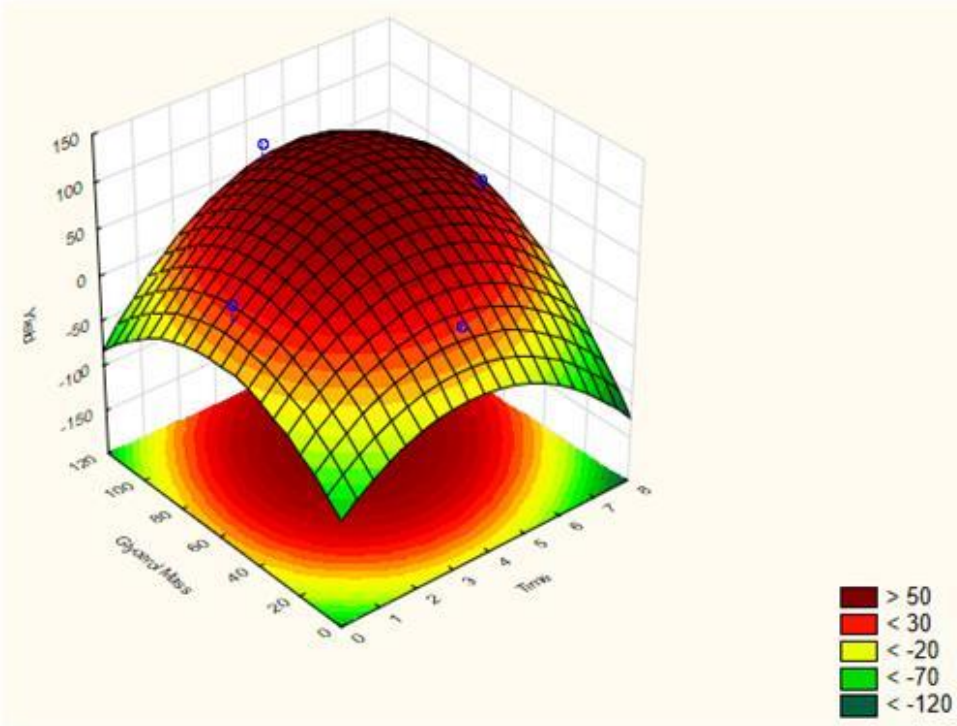

Figure 10 3D Surface Correlation between Synthesis Temperature and Glycerol Mass to GML Yield

\subsection{Variable Condition Optimization}

The dealumination process of the catalyst is expected to produce zeolite $\mathrm{Y}$ catalyst with a greater $\mathrm{Si} / \mathrm{Al}$ ratio, so as to increase the ability of catalysts to synthesize GML. Therefore, process variables need to be limited.

Optimizing the most significance variables in this research is achieved by using desirability profiling in
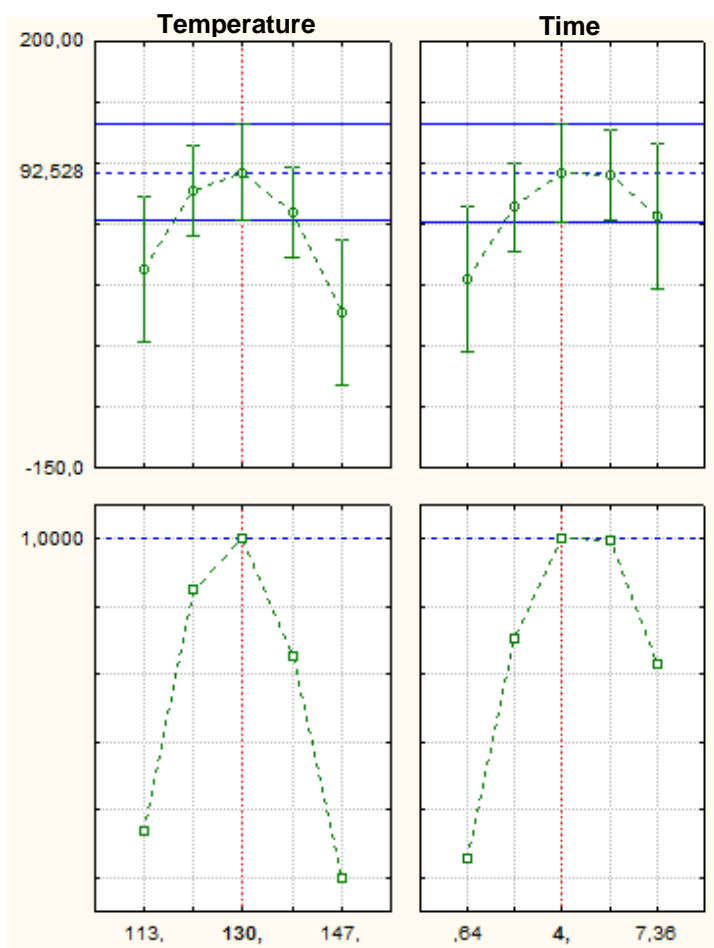

the statistica software. Figure 11 determined that the optimum conditions are synthesis temperature is limited between $113-147^{\circ} \mathrm{C}$, synthesis time within 0,64 to $7,36 \mathrm{~h}$ and glycerol mass within 14,9373 to 111,8927 g.

According Figure 11, the optimum condition obtained is $130^{\circ} \mathrm{C}$ for synthesis temperature, 4 hours for synthesis time and $87,654 \mathrm{~g}$ for glycerol mass, which the GML yield obtained is $90,75 \%$.
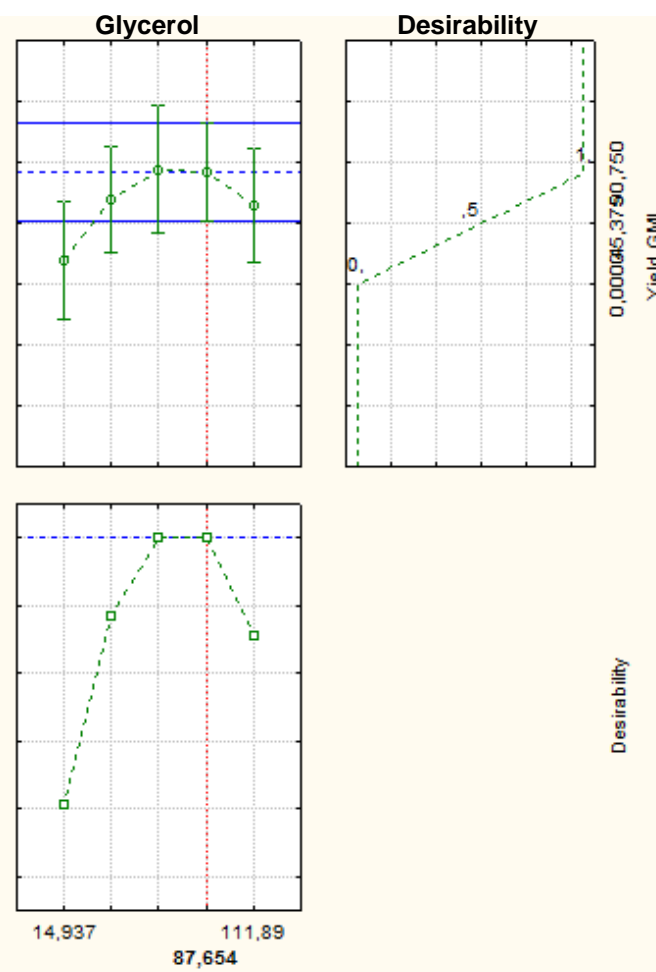

Figure 11 Optimization Using Response Desirability Profiling in Statistica 6.0 


\subsection{CONCLUSION}

The synthesis temperature, synthesis time, and mole ratio of lauric acid with glycerol affect the yield of GML produced. The most influential variable in the optimization of GML synthesis is the temperature variable. In the optimization process, the optimization conditions for GML synthesis using a dealuminated zeolite $Y$ catalyst obtained optimum conditions for the synthesis temperature of $130^{\circ} \mathrm{C}$, synthesis time of 4 hours, and mole ratio of lauric acid: mole of glycerol was 1: 7.5 (with lauric acid mass of $25 \mathrm{~g}$ and the glycerol mass was $87,654 \mathrm{~g}$ ). The relationship between operating variables to the GML yield response can be expressed in the 2nd order polynomial mathematical equation.

\section{Acknowledgement}

The authors would like to gratitude to non APBN of Diponegoro University fiscal year 2018 for the financial support (SPK No: 474-46/UN7.P4.3/PP/2018).

\section{References}

[1] Clarke, A. 2006. Minimal Inhibitory Concentration of Fatty acids in Mother's Milk Againsts Some Microorganisms In Lauricidin, The Natural Way To Better Health; http://www.lauricidi.com, 2402-2006.

[2] Nakamura, R., Komura, K., \& Sugi, Y. 2008. The Esterification of Glycerin with Lauric Acid Catalyzed by Multi Valent Metal Salts. Selective Formation of Mono and Dilaurins. Catalysis Communications. 9: 511-515. DOI:10.1016/j.catcom.2007.03.024.

3] Zhao, L., Chen, Y., Wang, B., Sun, C., Chakraborty, S., Ramasubramanian, K., Dutta, P.K., \& Ho, W. 2015. Multilayer Polymer/Zeolite $Y$ Composite Membrane Structure for $\mathrm{CO}_{2}$ Capture from Flue Gas. Journal of Membrane Science. 498: 1-13. DOI: 10.1016/j.memsci.2015.10.006.
[4] Tempelman, C. H. L., Zhu, X., Gudun, K., Mezari, B., Shen, B., \& Hensen, E. J. M. 2015. Texture, Acidity and Fluid Catalytic Cracking Performance of Hierarchical Faujasite Zeolite Prepared by an Ampiphilic Organosilane. Fuel Processing Technology. 04598: $11 . \quad \mathrm{DOl}$ 10.1016/j.fuproc.2015.06.025.

[5] Silaghi, M.-C., Chizallet, C., \& Raybaud, P. 2014. Challenges on Molecular Aspects of Dealumination and Desilication of Zeolites. Microporous and Mesoporous Materials. 191:82-96. DOI: 10.1016/j.micromeso.2014.02.040.

[6] Lestari, D. Y. 2010. Kajian Modifikasi dan Karakterisasi Zeolit Alam dari Berbagai Negara. Proceedings of Seminar Nasional Kimia dan Pendidikan Kimia; 30 October 2010; Yogyakarta, Indonesia; Yogyakarta States University.

[7] Machado, M. d. S., Pariente, J. P., Sastre, E., Cardoso, D. \& de Guerenu, A. M. 2000. Selective Synthesis of Glycerol Monolaurate with Zeolitic Molecular Sieves. Applied Catalysis. 203:321-328. DOI: 10.1016/\$0926-860X(00)004932.

[8] Istadi. Teknologi Katalis untuk Konversi Energi: Fundamental dan Aplikasi. 2011. Yogyakarta: Graha IImu.

[9] Anggoro, D. D., Setianto, W. B., Wibowo, T., Buchori, L. Pratama, F. R., \& Giovanno, A. 2017. Characterization and Testing of Zeolite $Y$ Dealuminate Catalysts for Glycerol Conversion to Glycerol Mono Laurate. Advanced Science Letters. 23(6): 5602-5604. DOI: 10.1166/asl.2017.8779

[10] Murphy, T.D. 1977.Design and Analysis of Industrial Experiments. Chemical Engineering. June: 168-182.

[11] Burtis, C. A., Bostick, W. D., Overton, J. B., \& Mrochek, J. E. Optimization of a Kinetic Method by Response Surface Methodology and Centrifugal Analysis and Application to the Enzymic Measurement of Ethanol. Analytical Chemistry. 53(8):1154-1159. DOI: 10.1021/ac00231a004.

[12] Cornell, J. A. 1990. How to Apply Response Surface Methodology. rev edition. Milwaukee, WI: American Society for Quality Control.

[13] Box, G. E. P., Hunter, W. G., \& Hunter, J. S. 1978. Statistics for Experimenters: an Introduction to Design, Data Analysis, and Model Building. New York: Wiley.

[14] Amin, N. A. S., \& Anggoro, D. D. 2002. Dealuminated ZSM-5 Zeolite Catalyst for Ethylene Oligomerization to Liquid Fuels. Journal of Natural Gas Chemistry. 11: 79-86.

[15] Haaland, P. D. 1989. Experimental Design in Biotechnology. New York: Marcel Dekker. 